\title{
Biliary tract cancer treatment: 5,584 results from the Biliary Tract Cancer Statistics Registry from 1998 to 2004 in Japan
}

\author{
Shuichi Miyakawa $\cdot$ Shin Ishihara \\ Akihiko Horiguchi · Tadahiro Takada • \\ Masaru Miyazaki · Takukazu Nagakawa
}

Received: 1 June 2008/Accepted: 1 July 2008/Published online: 26 December 2008

(C) Springer 2008

\begin{abstract}
Background/Purpose The results from the Japanese Biliary Tract Cancer Statistics Registry from 1988 to 1998 were reported in 2002. In the present study, we report here selectively summarized data as an overview of the 2006 follow-up survey of the registered cases from 1998 to 2004 for information bearing on problems with the treatment of cancer of the biliary tract.

Methods A total of 5,584 patients were registered from 1998 to 2004. The site of cancer was the bile duct in 2,732 patients, the gallbladder in 2,067, and the papilla of Vater in 785 . Those cases were analyzed with regard to patient survival according to the extent of tumor invasion (pT), the extent of lymph node metastasis $(\mathrm{pN})$ and the stage.

Results The five-year survival rate after surgical resection was $33.1 \%$ for bile duct cancer, $41.6 \%$ for gallbladder cancer, and $52.8 \%$ for cancer of the papilla of Vater. For hilar or superior bile duct cancer, the 5-year survival rate was lower with an increase in the $\mathrm{pT}, \mathrm{pN}$ and $\mathrm{f}$ stage,
\end{abstract}

S. Miyakawa $(\varangle) \cdot$ S. Ishihara $\cdot$ A. Horiguchi Department of Biliary and Pancreatic Surgery, Fujita Health University, 1-98 Dengakugakubo, Kutsukake-cho, Toyoake, Aichi 470-1192, Japan e-mail: smiyaka@fujita-hu.ac.jp

T. Takada

Department of Surgery, Teikyo University,

Tokyo, Japan

M. Miyazaki

Department of General Surgery,

Graduate School of Medicine, Chiba, Japan

T. Nagakawa

Fukuno Hospital, Nanto, Japan except pT3 vs. pT4, pN1 vs. pN2 and stage III vs. stage IVa. For middle or distal bile duct cancer, the 5-year survival rate was lower with increase in $\mathrm{pT}, \mathrm{pN}$ and $\mathrm{f}$ stage, except pT2 vs. pT3, pN2 vs. pN3, stage II vs. stage III and stage III vs. stage IVa. For gallbladder cancer, the 5-year survival rate was lower with increase in $\mathrm{pT}, \mathrm{pN}$ and $\mathrm{f}$ stage. For cancer of the papilla of Vater, the 5-year survival rate was lower with increase in $\mathrm{pT}, \mathrm{pN}$ and $\mathrm{f}$ stage, except $\mathrm{pT} 1$ vs. pT2, pN1 vs. pN2, and stage III vs. stage IVa.

Conclusions In the present study, the outcomes of surgical treatment were better than that of the previous report from Japan and foreign countries. The $\mathrm{pT}, \mathrm{pN}$ and stage of gallbladder cancer are well defined. However, there were no significant differences in some groups of those of bile duct cancer and cancer of the papilla of Vater.

Keyword Biliary tract cancer - Statistics registry · 5-year survival $\cdot$ Stage of disease $\cdot$ Lymph node metastasis

\section{Introduction}

To improve the surgical results, the Japanese Society of Biliary Surgery (JSBS) was established in 1981. In 1987, the JSBS began registration of biliary tract carcinomas as one of its projects in Japan. In this project, the Society has established guidelines for the treatment of cancer of the biliary tract based on the extent of involvement at each anatomical site. Nagkawa et al. [1] reported results from the Biliary Tract Cancer Statistics Registry from 1988 to 1998 in Japan. Thereafter, the fifth Japanese edition of the Japanese General Rules for Biliary Tract Cancer [2], which was translated in the second English edition [3], which was published in 2004. In this edition, major revisions were made for the degree of determinants of tumor extension 
and $\mathrm{T}$ factors, lymph node metastasis, and stage classification with regard to descriptions for which evidence was obtained.

In the present study, we analyzed data of the follow-up survey which performed in 2006 to the registered patients of biliary tract cancer from 1998 to 2004 in Japan for verification of the new version, and for information bearing on problems with treatment of cancer of the biliary tract.

\section{Methods}

\section{Patients}

Case registration is performed every year. Follow-up survey is performed in alternate years. A total of 5,584 cases were registered for the 7 years from 1998 to 2004 . The site of cancer was the bile duct in 2,732 cases, the gallbladder in 2,067 cases, and the papilla of Vater in 785 cases. Of patients with bile duct cancer, 1,816 were males and 912 were females, and the male-to-female ratio was 1.99:1. Among patients with gallbladder cancer, 861 were males and 1,201 were females, with a male-to-female ratio of $1: 1.39$. Among patients with cancer of the papilla of Vater, 414 were males and 370 were females, with a male-tofemale ratio of 1.12:1. In the case of bile duct cancer, peak incidence occurred in patients in their 60s to 70 s. Gallbladder cancer exhibited peak incidence in the 70s. Cancer of the papilla of Vater exhibited peak incidence in the 60 s. Patients that had complete staging and follow-up information available for survival analysis were 3,992 (71.5\%). The most of insufficient data were lost to follow-up.

These cases were analyzed in regard to patient survival according to the primary tumor invasion, the stage of disease and the extent of lymph node metastasis. The extent of tumors, including the classification of lymph node metastasis, was classified cording to the fifth edition of Japanese General Rules for Classification of Biliary Tract Carcinoma currently used in Japan.

The survival rate was calculated by the Kaplan-Meier method. Statistical analysis was performed using the logrank test for survival rate. $P$ values less than 0.05 were considered significant.

\section{Results}

Outline of registered cases

Table 1 shows the rates of resection, rates of curative resection, and operative death rates. Surgical resections were performed in $70.2 \%$ of cases with bile duct cancer, $68.8 \%$ with gallbladder cancer, and $89.4 \%$ with cancer of the papilla of Vater. Curative resection rates were $68.1 \%$ in bile duct cancer, $68.7 \%$ in gallbladder cancer, and $93.0 \%$ in cancer of the papilla of Vater. Operative mortality was $0.6 \%$.

Figure 1 shows survival rate after surgical resection. Five-year survival rate was $33.1 \%$ for bile duct cancer, $41.6 \%$ for gallbladder cancer, and $52.8 \%$ for cancer of the papilla of Vater. There were significant differences between sites of cancer.

Survival of patients with resection according to site

\section{Gallbladder cancer}

1. Histological primary tumor invasion (pT) and lymph node metastasis $(\mathrm{pN})$

The degree of tumor invasion around the gallbladder was most frequently pT2 (39.6\%), followed by pT4 (32.6\%). Thus, $44.4 \%$ of all cases were rated as pT3 or higher. By degree of tumor invasion around the gallbladder, 5-year survival rates were $85.9 \%$ in pT1 patients, $56.1 \%$ in pT2, $19.2 \%$ in pT3, and $14.1 \%$ in pT4. There were significant differences between the four groups (Table 2).

After tumor resection, lymph node metastasis was present in $38.7 \%$ of all cases. Table 2 shows prognosis in relation to lymph node metastasis. The 5-year survival rate was $60.3 \%$ for $\mathrm{pN} 0$ patients, $30.0 \%$ for $\mathrm{pN} 1,16.8 \%$ for $\mathrm{pN} 2$, and $5.9 \%$ for $\mathrm{pN} 3$. There were significant differences between the four groups.

2. Overall tumor stage (f stage)

The $\mathrm{f}$ stage was most frequently rated $\mathrm{IVb}$ patients (25.4\%), followed by II (24.1\%), IVa (20.0\%), I (16.2\%),
Table 1 Registered cases of biliary tract cancer (1998-2004)

\begin{tabular}{lcrrrr}
\hline Tumor site & $\begin{array}{l}\text { Number of } \\
\text { registry cases }\end{array}$ & $\begin{array}{l}\text { Number of } \\
\text { complete data }\end{array}$ & Resection rate & $\begin{array}{l}\text { Curative } \\
\text { resection rate }\end{array}$ & \multicolumn{1}{c}{$\begin{array}{l}\text { Death } \\
\text { rate }\end{array}$} \\
\hline Gallbladder & 2,067 & $1,590(76.9 \%)$ & $1,094(68.8 \%)$ & $752(68.7 \%)$ & $8(0.7 \%)$ \\
Bile duct & 2,732 & $1,894(69.3 \%)$ & $1,299(70.2 \%)$ & $884(68.1 \%)$ & $7(0.5 \%)$ \\
Papilla of Vater & 785 & $553(70.4 \%)$ & $515(89.4 \%)$ & $479(93.0 \%)$ & $2(0.4 \%)$ \\
Total & 5,584 & $3,992(71.5 \%)$ & $2,908(72.8 \%)$ & $1,402(72.7 \%)$ & $17(0.6 \%)$ \\
\hline
\end{tabular}




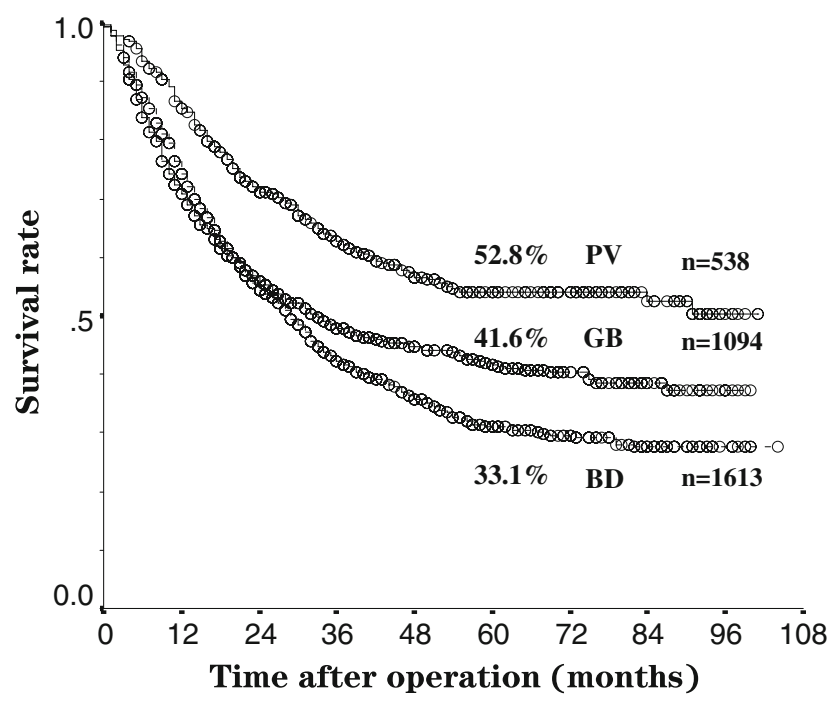

Fig. 1 Survival of patients with resection of gallbladder cancer, bile duct cancer, and cancer of the papilla of Vater. Percentages show 5year survival rates. There were significant differences between sites of cancer. $\mathrm{BD}$ versus $\mathrm{GB}, P=0.0320$; $\mathrm{BD}$ versus $\mathrm{PV}, P<0.0001$; GB versus $\mathrm{PV}, P<0.0001 ; \mathrm{BD}$, bile duct cancer; $\mathrm{GB}$, gallbladder cancer; $\mathrm{PV}$, cancer of papilla of Vater

Table 2 Survival according to histological tumor invasion around the bile duct (pT) and histological lymph node metastasis (pN) of gallbladder cancer

\begin{tabular}{ccccc}
\hline \multirow{2}{*}{ No. of patients } & \multicolumn{3}{l}{ Survival rate $(\%)$} \\
\cline { 3 - 5 } & & 1 year & 3 year & 5 year \\
\hline pT & & 98.8 & 91.2 & $85.9^{*}$ \\
1 & 167 & 82.7 & 63.7 & $56.1^{*}$ \\
2 & 415 & 60.2 & 27.6 & $19.2^{*}, * *$ \\
3 & 124 & 49.4 & 19.0 & $14.1^{* *}$ \\
4 & 341 & & & \\
pN & & 83.9 & 66.6 & $60.3^{*}$ \\
0 & 595 & 65.9 & 37.2 & $30.0^{*, \dagger}$ \\
1 & 126 & 52.8 & 21.3 & $16.8^{\dagger, \dagger}$ \\
2 & 178 & 44.6 & 11.1 & $5.9^{\dagger \dagger}$ \\
3 & 101 & &
\end{tabular}

There were significant differences between the four $\mathrm{pT}$ group There were significant differences between the four $\mathrm{pN}$ group ${ }^{*} P<0.0001 ; * * P=0.0117 ;{ }^{\dagger} P=0.0074 ;{ }^{\dagger} P=0.0157$

and III (14.5\%). Thus, $59.9 \%$ of all cases were rated as $\mathrm{f}$ stage III or higher. Figure 2 shows prognosis in relation to $f$ stage. The 5 -year survival rate was $87.5 \%$ for $f$ stage I patients, $68.7 \%$ for $\mathrm{f}$ stage II, $41.8 \%$ for $\mathrm{f}$ stage III, $23.3 \%$ for $\mathrm{f}$ stage IVa, and $6.3 \%$ for $\mathrm{f}$ stage $\mathrm{IVb}$. There were significant differences between the five groups (Fig. 2).

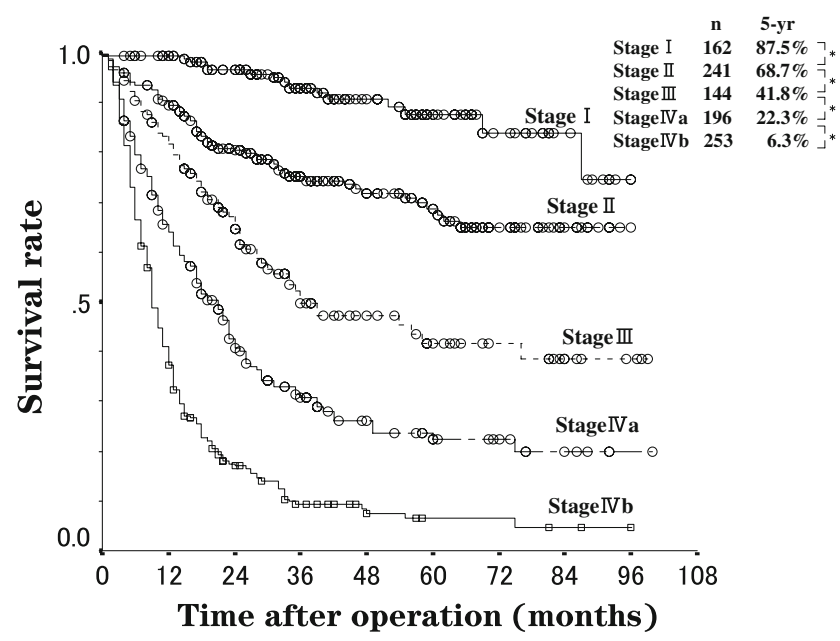

Fig. 2 Survival according to overall tumor stage (f stage) of gallbladder cancer. There were significant differences between five f stages. $* P<0.0001$

Bile duct cancer

Hilar or superior bile duct cancer

1. Histological tumor invasion around the bile duct (pT) and lymph node metastasis $(\mathrm{pN})$

The degree of tumor invasion around the bile duct was most frequently pT4 patients $(40.6 \%)$, followed by pT2 $(32.5 \%)$. By degree of tumor invasion around the bile duct, 5-year survival rates were $66.6 \%$ in pT1 patients, $38.3 \%$ in pT2, $26.0 \%$ in pT3, and $14.9 \%$ in pT4 (Table 3). Five-year survival rate decreased significantly as pT became higher, although the difference between pT3 and 4 was not significant.

After tumor resection, lymph node metastasis was present in $40.2 \%$ of all cases. Table 3 shows prognosis in relation to lymph node metastasis. The 5-year survival rate was $38.2 \%$ for $\mathrm{pN} 0$ patients, $17.6 \%$ for $\mathrm{pN} 1,10.2 \%$ for $\mathrm{pN} 2$, and $8.3 \%$ for $\mathrm{pN} 3$. The five-year survival rate of each $\mathrm{pN}$ group was significantly lower with increase in extent of lymph node metastasis, except for lack of significant difference between $\mathrm{pN} 1$ and 2 .

\section{Overall tumor stage (f stage)}

The f stage was most frequently rated IVa patients (31.7\%), followed by III (23.5\%), II (20.1\%), IVb (19.4\%), and I (5.3\%). Thus, $48.8 \%$ of all cases were rated as $f$ stage IVa or higher. Figure 3 shows prognosis in relation to $f$ stage. The 5-year survival rate was $73.8 \%$ for $\mathrm{f}$ stage I patients, $43.3 \%$ for $\mathrm{f}$ stage II, $30.5 \%$ for $\mathrm{f}$ stage III, $23.3 \%$ for $f$ stage IVa, and $7.2 \%$ for $f$ stage IVb. The five-year survival rate decreased significantly as $f$ stage became higher, although the difference between $\mathrm{f}$ stages III and IVa was not significant. 
Table 3 Survival according to histological tumor invasion around the bile duct $(\mathrm{pT})$ and histological lymph node metastasis $(\mathrm{pN})$ of hilar or superior bile duct cancer

\begin{tabular}{cclll}
\hline & No. of patients & \multicolumn{3}{l}{ Survival rate $(\%)$} \\
\cline { 3 - 5 } & & 1 year & 3 year & 5 year \\
\hline pT & & & & \\
1 & 42 & 78.0 & 72.7 & $66.6^{*}$ \\
2 & 169 & 69.6 & 52.8 & $38.3^{*}, * *$ \\
3 & 98 & 64.1 & 35.3 & $26.0^{* *}$ \\
4 & 211 & & & 14.9 \\
$\mathrm{pN}$ & & 78.6 & 50.1 & $38.2^{\dagger}$ \\
0 & 311 & 66.9 & 24.9 & $17.6^{\dagger}$ \\
1 & 101 & 62.2 & 29.8 & $10.2^{\dagger \dagger}$ \\
2 & 64 & 47.7 & 12.4 & $8.3^{\dagger \dagger}$ \\
3 & 44 & &
\end{tabular}

There were significant differences between pT1 and 2 and between pT2 and 3

There were significant differences between $\mathrm{pNO}$ and 1 and between $\mathrm{pN} 2$ and 3

* $P=0.0228 ; * * P=0.0124 ;{ }^{\dagger} P<0.0001 ;{ }^{\dagger \dagger} P=0.0436$

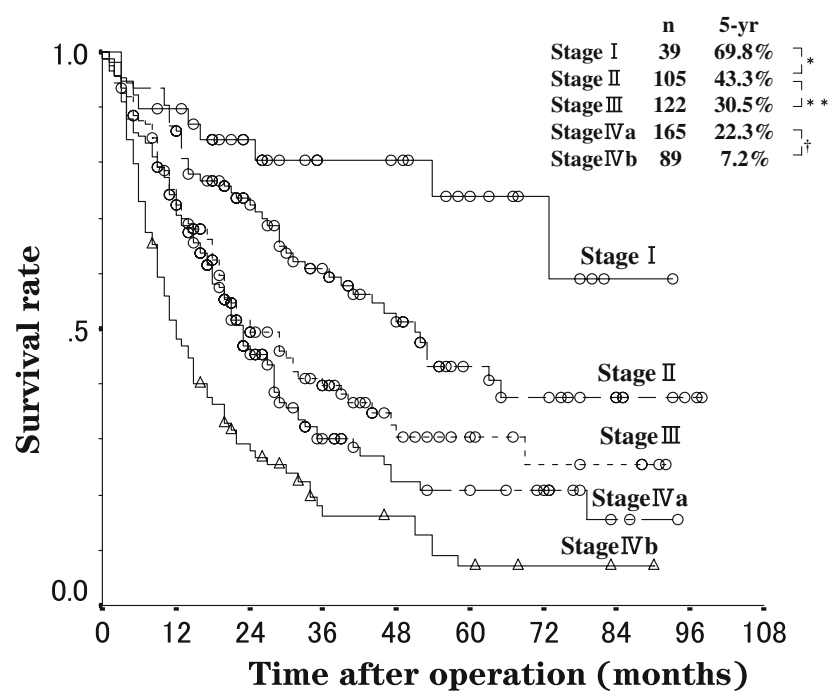

Fig. 3 Survival according to overall tumor stage (f stage) of hilar or superior bile duct cancer. The five-year survival rate decreased significantly as $\mathrm{f}$ stage became higher, although the difference between $\mathrm{f}$ stages III and IVa was not significant. * $P=0.0295$; ** $P=0.0048 ;{ }^{\dagger} P=0.001$

\section{Middle or distal bile duct cancer}

1. Histological tumor invasion around the bile duct (pT) and lymph node metastasis $(\mathrm{pN})$

The degree of tumor invasion around the bile duct was most frequently pT2 patients $(35.9 \%)$, followed by pT4 (27.9\%), pT3 $(27.0 \%)$. Thus, $54.9 \%$ of all cases were rated as pT3 or higher. By degree of tumor invasion around the
Table 4 Survival according to histological tumor invasion around the bile duct $(\mathrm{pT})$ and histological lymph node metastasis $(\mathrm{pN})$ of middle or distal bile duct cancer

\begin{tabular}{ccccc}
\hline & No. of patients & \multicolumn{3}{l}{ Survival rate $(\%)$} \\
\cline { 3 - 5 } & & 1 year & 3 year & 5 year \\
\hline pT & & & & \\
1 & 72 & 90.2 & 85.1 & $55.6^{*}$ \\
2 & 280 & 82.9 & 63.9 & $36.2^{*}$ \\
3 & 210 & 74.9 & 56.6 & $33.7^{* *}$ \\
4 & 217 & 63.1 & 36.7 & $20.8^{* *}$ \\
pN & & & & \\
0 & 478 & 81.6 & 52.4 & $40.1^{\dagger}$ \\
1 & 128 & 77.7 & 39.3 & $23.4^{\dagger, \dagger}$ \\
2 & 98 & 58.2 & 22.0 & $19.2^{\dagger \dagger}$ \\
3 & 75 & 58.9 & 20.6 & 18.1 \\
\hline
\end{tabular}

There were significant differences between pT1 and 2 and between pT3 and 4

There were significant differences between $\mathrm{pN} 0$ and 1 and between pN1 and 2

* $P=0.0053 ; * * P=0.0002 ;{ }^{\dagger} P=0.0036 ;{ }^{\dagger} P=0.0009$

bile duct, the 5-year survival rates were $55.6 \%$ in pT1 patients, $36.2 \%$ in pT2, $33.7 \%$ in pT3, and $20.8 \%$ in pT4 (Table 4). The five-year survival rate decreased significantly as pT became higher, although the difference between pT2 and 3 was not significant.

Table 4 shows prognosis in relation to lymph node metastasis. The 5-year survival rate was $40.1 \%$ for $\mathrm{pN} 0$ patients, $23.4 \%$ for $\mathrm{pN} 1,19.2 \%$ for $\mathrm{pN} 2$, and $18.1 \%$ for $\mathrm{pN} 3$. The 5-year survival rate of each $\mathrm{pN}$ group was significantly lower with increase in extent of lymph node metastasis, except for lack of significant difference between pN2 and 3 .

2. Overall tumor stage (f stage)

The $\mathrm{f}$ stage was most frequently rated III patients (31.3\%), followed by II $(23.9 \%)$, IVa (22.0\%), IVb $(14.0 \%)$, and I $(8.9 \%)$. Thus, $67.3 \%$ of all cases were rated as f stage III or higher. Figure 4 shows prognosis in relation to $\mathrm{f}$ stage. The 5-year survival rate was $59.5 \%$ in $\mathrm{f}$ stage I patients, $39.3 \%$ in f stage II, $32.6 \%$ in f stage III, $29.6 \%$ in $\mathrm{f}$ stage IVa, and $9.7 \%$ in $\mathrm{f}$ stage IVb. The 5-year survival rate decreased significantly as f stage became higher, although the differences between $f$ stages II and III and between $\mathrm{f}$ stages III and IVa were not significant.

\section{Cancer of the papilla of Vater}

1. Histological tumor invasion (pT) and lymph node metastasis $(\mathrm{pN})$

The degree of tumor invasion around the papilla of Vater was most frequently pT3 patients (37.7\%), followed 


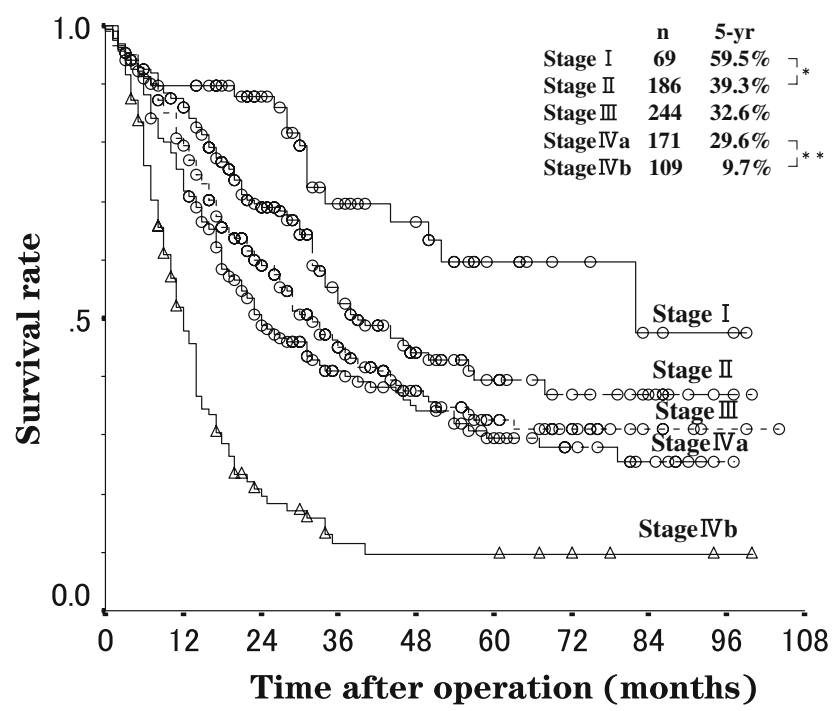

Fig. 4 Survival according to overall tumor stage (f stage) of middle or distal bile duct cancer. The 5-year survival rate decreased significantly as $\mathrm{f}$ stage became higher, although the differences between $\mathrm{f}$ stages II and III and between $\mathrm{f}$ stages III and IVa were not significant. $* P=0.0172 ; * * P<0.0001$

Table 5 Survival according to histological tumor invasion around the bile duct (pT) and histological lymph node metastasis $(\mathrm{pN})$ of cancer of the papilla of Vater

\begin{tabular}{crlll}
\hline & No. of patients & \multicolumn{3}{l}{ Survival rate $(\%)$} \\
\cline { 3 - 5 } & & 1 year & 3 year & 5 year \\
\hline pT & & & & \\
1 & 141 & 95.0 & 78.6 & 74.1 \\
2 & 99 & 93.9 & 75.7 & $62.6^{*}$ \\
3 & 194 & 83.2 & 58.8 & $49.5^{* * * *}$ \\
4 & 81 & 65.0 & 30.8 & $19.7^{* *}$ \\
$\mathrm{pN}$ & & & & \\
0 & 294 & 88.7 & 76.3 & $68.7^{* *}$ \\
1 & 86 & 84.7 & 44.4 & $34.5^{* *}$ \\
2 & 74 & 78.0 & 40.7 & $30.9^{\dagger}$ \\
3 & 45 & 61.9 & 21.4 & $0^{\dagger}$ \\
\hline
\end{tabular}

There were significant differences between pT 2 and pT 3 and between pT3 and 4

There were significant differences between $\mathrm{pN} 0$ and 1 and between $\mathrm{pN} 2$ and 3

* $P=0.0139 ; * * P<0.0001{ }^{\dagger}{ }^{\dagger} P=0.0054$

by pT1 (27.4\%), pT2 (19.2\%), pT4 (15.7). By degree of tumor invasion around the papilla of Vater, 5-year survival rates (Table 5) were $74.1 \%$ in pT1 patients, $62.6 \%$ in pT2, $49.5 \%$ in pT3, and $19.7 \%$ in pT4. Five-year survival rate decreased significantly as $\mathrm{pT}$ became higher, although the difference between pT1 and 2 was not significant.

Table 5 shows prognosis in relation to lymph node metastasis. The 5-year survival rate was $68.7 \%$ for $\mathrm{pN} 0$

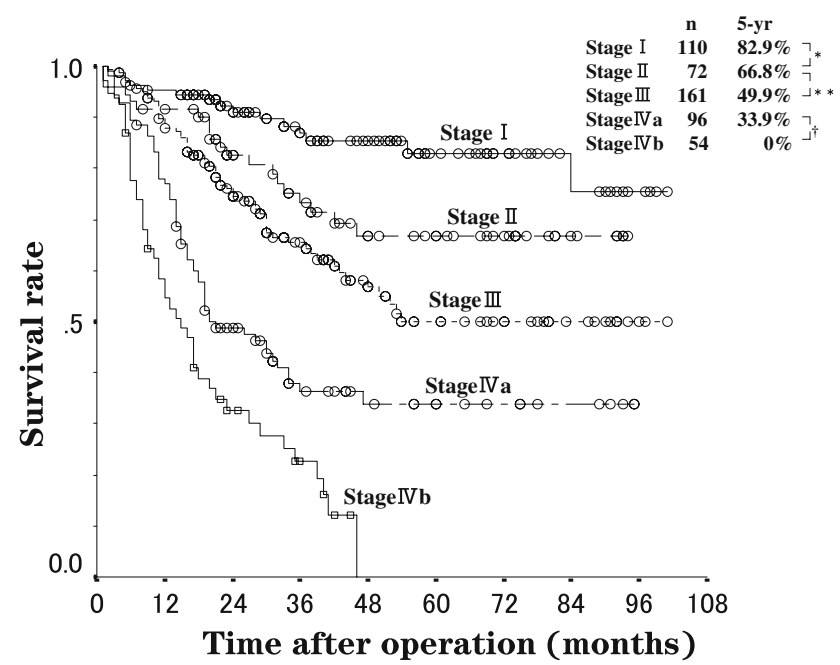

Fig. 5 Survival according to overall tumor stage (f stage) of cancer of the papilla of Vater. The 5-year survival rate of each $f$ stage group was significantly lower with an increase in $\mathrm{f}$ stage, except for the lack of significant difference between $\mathrm{f}$ stages II and III. * $P=0.0333$; $* * P=0.0001 ;{ }^{\dagger} P=0.0025$

patients, $34.5 \%$ for $\mathrm{pN} 1,30.9 \%$ for $\mathrm{pN} 2$, and $0 \%$ for $\mathrm{pN} 3$. Thus, none of the patients with $\mathrm{pN} 3$ disease survived for 5 years. The 5 -year survival rate of each $\mathrm{pN}$ group was significantly lower with an increase in the extent of lymph node metastasis, except for lack of significant difference between $\mathrm{pN} 1$ and 2 .

\section{Overall tumor stage (f stage)}

The f stage was the most frequently of rated III patients (32.7\%), followed by I (22.3\%), IVa (19.5\%), II (14.6\%), and IVb (11.0\%). Figure 5 shows the prognosis in relation to $\mathrm{f}$ stage. The 5-year survival rate was $82.9 \%$ in $\mathrm{f}$ stage $\mathrm{I}$ patients, $66.8 \%$ in $\mathrm{f}$ stage II, $49.9 \%$ in $\mathrm{f}$ stage III, $33.9 \%$ in $\mathrm{f}$ stage IVa, and $0 \%$ in $\mathrm{f}$ stage IVb. Thus, none of the patients with $\mathrm{f}$ stage $\mathrm{IVb}$ disease survived for 5 years. The 5 -year survival rate of each $f$ stage group was significantly lower with increase in $f$ stage, except for the lack of significant difference between $\mathrm{f}$ stage II and III.

\section{Discussion}

By two recent reports $[4,5]$ from the National Cancer Database (NCDB) and Surveillance, Epidemiology, and End Results (SEER) database of America, the complete records were $70.7 \%$ and $72.6 \%$. In this study, patients that had complete staging and follow-up information available for survival analysis were 3,992 (71.5\%). Precision in our study was approximately equal with these reports. The most of insufficient data of our study were lost to follow-up. An effort to minimize a loss of follow-up in each institution is necessary to put up precision of registration data. 
In the previously report of Japanese registry [1], the resection rate and the curative resection rate were $69.8 \%$ and $37.7 \%$ for gallbladder cancer, $67.0 \%$ and $30.4 \%$ for bile duct cancer, and $91.2 \%$ and $78.5 \%$ for cancer of papilla of Vater. In this study, the resection rates were higher than those for bile duct cancer and gallbladder cancer, and the curative resection rates were higher than those for cancer of all site of the biliary tract. Operative mortality decreased during the period between 1988 to 1998 and 1998 to 2004 from $1.7 \%$ to $0.6 \%$, suggesting that surgical treatment for biliary tract cancer can now be conducted very safely. The 5-year survival rates following resection were 7.1 point up in the bile duct cancer, 0.4 point down in gallbladder cancer, and 1.8 point up in ampullary cancer, compared with previous report of Japanese registry. In this study, the survival data showed remarkable improvement in all patients with bile duct cancer who underwent resection. Previous survival rates of the gallbladder cancer were $77 \%$ in stage I, 53\% in stage II, $31 \%$ in stage III, and $9 \%$ in stage IV, and the survival rates showed more than 10 points improvement in stage I-IVa in present study. In hilar or superior bile duct cancer, previous survival rate were $47 \%, 30 \%, 19 \%$, and $12 \%$ in stage I to IV, and also, in this study, those showed remarkable improvement in stage I to IVa. In middle or lower bile duct cancer, previous survival rate were $54 \%, 33 \%, 20 \%$, and $15 \%$ in stage I to IV, and in this study, those showed improvement of the points from 5.5 to 13 in stage I to IVa. In cancer of papilla of Vater, previous survival rate were $75 \%, 48 \%, 34 \%$, and $19 \%$ in stage I to IV, and in this study, those showed remarkable improvement in stage I to IVa.

Foreign reports presenting data on 100 or more cases include four reports on hilar or superior bile duct cancer (104-151 cases each) [6-9], four reports on middle and distal bile duct cancer (104-239 cases each) [10-13], four reports on gallbladder cancer (117-724 cases each) [14-17], and eight reports on ampullary cancer (101-163 cases each) [18-26]. None of these reports was superior to the present study in terms of scale of study. According to these reports, the five-year survival rate after resection was $11.0-25.6 \%$ for hilar or superior bile duct cancer, 21.0$27.0 \%$ for middle and distal bile duct cancer, $5.0-38.0 \%$ for gallbladder cancer, and $33.0-68.0 \%$ for ampullary cancer. In the present study, the five-year survival rate after resection was $28.6 \%$ for hilar or superior bile duct carcinoma, $32.7 \%$ for middle or distal bile duct cancer, $41.6 \%$ for gallbladder cancer, and $52.8 \%$ for ampullary cancer. Thus, five-year survival rates after resection were higher in the present study than in those foreign reports in the hilar or superior bile duct cancer, the middle or distal bile duct cancer, and the gallbladder cancer. The outcome of treatment of ampullary cancer was better in two foreign studies than in the present one. The best outcome (five-year survival rate: $68.0 \%$ ) was reported by Woo et al. in their analysis of 163 cases [13]. According to their report, depth of invasion was $\mathrm{T} 2$ or lower (as determined using criteria of the American Joint Committee on Cancer 6th edition) in $68 \%$ of all cases analyzed. In the present study, on the other hand, cases with $\mathrm{T} 3$ or higher depth of invasion accounted for $53.4 \%$ of all cases. Thus, the percentage of advanced cases was higher in the present study than in that of Woo et al. [25]. This difference may account for the higher fiveyear survival rate in their study. According to the report by Park et al. [24], the five-year survival rate for 102 cases was $57.0 \%$. They excluded cases of perioperative death when calculating this survival rate. Our survival rate, on the other hand, was calculated for the total population including patients who died perioperatively. This difference in method of calculation may explain the relatively poor outcome in our study. Compared to foreign studies, excluding those of Park et al. [24] and Woo et al. [25], the outcome in the present study was favorable. In the present study, the outcome of treatment was better than reported previously from Japan [1] and foreign countries [6-23].

As to appropriateness and problems of stage classification, the fifth edition of the Japanese General Rules for Biliary Tract Cancer maybe not needed major revision. The $\mathrm{pT}, \mathrm{pN}$, and stage in gallbladder cancer are well defined. In the other site, classification of those prognostic factors is not controversially, although there was no significant difference in survival rates between those prognostic factors. Further, detailed analysis is needed to improve the T-category, the lymph node groups, stage grouping and the outcome of treatment of bile duct cancer and cancer of the papilla of Vater.

The prognosis of biliary tract cancer remains poor. Sophisticated diagnostic skills and treatment methods and their application are naturally required to achieve better treatment results for biliary tract cancer. The Clinical Practice Guidelines for the Management of Biliary tract and Ampullary Carcinomas [26] was published in 2008. The guideline consists of diagnostic skills [27-29] and treatment methods [30-34] and their application. The management of biliary tract cancer based on this guideline can expect improvement of treatment outcome.

\section{References}

1. Nagakawa T, Kayahara M, Ikeda S, Futakawa S, Kakita A, Kawarada $\mathrm{H}$, et al. Biliary tract cancer treatment: results from the Biliary Tract Cancer Statistics Registry in Japan. J Hepatobiliary Pancreat Surg. 2002;9:569-75.

2. Japanese Society of Biliary Surgery. Classification of biliary tract carcinoma. 5th Japanese ed. Tokyo: Kanehara; 2003. 
3. Japanese Society of Biliary Surgery. Classification of biliary tract carcinoma. 2nd English ed. Tokyo: Kanehara; 2004.

4. Fong Y, Wagman L, Gonen M, Crawford J, Reed W, Swanson R, et al. Evidence-based gallbladder cancer staging: changing cancer staging by analysis of data from the national cancer database. Ann Surg. 2006;243:767-74.

5. Nathan H, Pawlik TM, Wolfgang CL, Choti MA, Cameron JL, Schulick RD. Trends in survival after surgery for cholangiocarcinoma: a 30-year population-based SEER database analysis. J Gastrointest Surg. 2007;11:1488-97.

6. Klempnauer J, Ridder GJ, von Wasielewski R, Werner M, Weimann A, Pichlmayr R. Resectional surgery of hailer cholangiocarcinoma: a multivariate analysis of prognostic factor. J Clin Oncol. 1997;15:947-54.

7. Lillemoe KD, Cameron JL. Surgery for hilar cholangiocarcinoma: the Johns Hopkins approach. J Hepatobiliary Pancreat Surg. 2000;7:115-21.

8. Launois B, Reding R, Lebeau G, Buard JL. Surgery for hilar cholangiocarcinoma: French experience in a collective survey of 552 extrahepatic bile duct cancers. J Hepatobiliary Pancreat Surg. 2000;7:128-34.

9. Lee SG, Lee YJ, Park KM, Hwang S, Min PC. One hundred and eleven liver resection for hilar bile duct cancer. J Hepatobiliary Pancreat Surg. 2000;7:135-41.

10. Fong Y, Blumgart LH, Lin E, Fortner JG, Brennan MF. Outcome of treatment for distal bile duct. Br J Surg. 1996;83:1712-5.

11. Wade TP, Prasad CN, Virgo KS, Johnson FE. Experience with distal bile duct cancers in US veterans affairs hospitals: 19871991. J Surg Oncol. 1997;64:242-5.

12. Cheng Q, Luo X, Zhang B, Jiang X, Yi B, Wu M. Distal bile duct carcinoma: prognostic factor after curative surgery. Ann Surg Oncol. 2006;14:1212-9.

13. DeOliveira ML, Cunningham SC, Cameron JL, Kamangar F, Winter JM, Lillemoe KD, et al. Cholangiocarcinoma: thirty-one year experience with 564 patients at single institution. Ann Surg. 2007;245:755-62.

14. Cubertafond P, Gainant A, Cucchiaro G. Surgical treatment of 724 carcinomas of the gallbladder: results of the French Surgical Association survey. Ann Surg. 1994;219:275-80.

15. Fong Y, Jarnagin W, Blumgart LH. Gallbladder cancer: comparison of patients presenting after prior noncurative intervention. Ann Surg. 2000;232:557-69.

16. Balachandran P, Agarwal S, Krishnani N, Pandey CM, Kumar A, Sikora SS, et al. Predictors of long-term survival in patients with gallbladder cancer. J Gastrointest Surg. 2006;10:848-54.

17. Principe A, Del Gaudio M, Ercolani G, Golfieri R, Cucchetti A, Pinna AD. Radical surgery for gallbladder carcinoma: possibilities of survival. Hepatogastroenterology. 2006;53:660-4.

18. Talamini MA, Moesinger RC, Pitt HA, Sohn TA, Hruban RH, Lillemoe KD, et al. Adenocarcinoma of the ampulla of Vater: a 28-year experience. Ann Surg. 1997;225:590-600.

19. Howe JR, Klimstra DS, Moccia RD, Conlon KC, Brennan MF. Factors predictive of survival in ampullary carcinoma. Ann Surg. 1998;228:87-94.

20. Beger HG, Treitschke F, Gansauge F, Harada N, Hiki N, Mattfeldt T. Tumor of the ampulla of Vater: experience with local or radical resection in 171 consecutively treated patients. Arch Surg. 1999;134:526-34.

21. Qiao QL, Zhao YG, Ye ML, Yang YM, Zhao JX, Huang YT, et al. Carcinoma of the ampulla of Vater: factors influencing long-term survival of 127 patients with resection. World J Surg. 2006;31:137-43.

22. Balachandran P, Sikora SS, Kapoor S, Krishnani N, Kumar A, Saxena R, et al. Long-term survival and recurrence patterns in ampullary cancer. Pancreas. 2006;32:390-5.

23. Hsu HP, Yang TM, Hsieh YH, Shan YS, Lin PW. Predictors for patterns of failure after pancreaticoduodenectomy in ampullary cancer. Ann Surg Oncol. 2006;14:50-60.

24. Park JS, Yoon DS, Kim KS, Choi JS, Lee WJ, Chi HS, et al. Factors influencing recurrence after curative resection for ampulla of Vater carcinoma. J Surg Oncol. 2007;95:286-90.

25. Woo SM, Ryu JK, Lee SH, Yoo JW, Park JK, Kim YT, et al. Recurrence and prognostic factors of ampullary carcinoma after radical resection: comparison with distal extrahepatic cholangiocarcinoma. Ann Surg Oncol. 2007;14:3195-201.

26. Takada T, Miyazaki M, Miyakawa S, Tsukada K, Nagino M, Kondo S, et al. Purpose, use, and preparation of clinical practice guidelines for the management of biliary tract and ampullary carcinomas. J Hepatobiliary Pancreat Surg. 2008;15:2-6.

27. Miyakawa S, Ishihara S, Takada T, Miyazaki M, Tsukada K, Nagino M, et al. Flowcharts for the management of biliary tract and ampullary carcinomas. J Hepatobiliary Pancreat Surg. 2008;15:7-14.

28. Miyazaki M, Takada T, Miyakawa S, Tsukada K, Nagino M, Kondo S, et al. Risk factors for biliary tract and ampullary carcinomas and prophylactic surgery for these factors. J Hepatobiliary Pancreat Surg. 2008;15:15-24.

29. Tsukada T, Takada T, Miyazaki M, Miyakawa S, Nagino M, Kondo S, et al. Diagnosis of biliary tract and ampullary carcinomas. J Hepatobiliary Pancreat Surg. 2008;15:26-30.

30. Nagino M, Takada T, Miyazaki M, Miyakawa S, Tsukada K, Kondo S, et al. Preoperative biliary drainage for biliary tract and ampullary carcinomas. J Hepatobiliary Pancreat Surg. 2008;15:31-40.

31. Kondo S, Takada T, Miyazaki M, Miyakawa S, Tsukada K, Nagino M, et al. Guidelines for the management of biliary tract and ampullary carcinomas: surgical treatment. J Hepatobiliary Pancreat Surg. 2008;15:41-54.

32. Furuse J, Takada T, Miyazaki M, Miyakawa S, Tsukada K, Nagino M, et al. Guidelines for chemotherapy of biliary tract and ampullary carcinomas. J Hepatobiliary Pancreat Surg. 2008;15:55-62.

33. Saito H, Takada T, Miyazaki M, Miyakawa S, Tsukada K, Nagino M, et al. Radiation therapy and photodynamic therapy for biliary tract and ampullary carcinomas. J Hepatobiliary Pancreat Surg. 2008;15:63-8.

34. Tsuyuguchi T, Takada T, Miyazaki M, Miyakawa S, Tsukada K, Nagino $M$, et al. Stenting and interventional radiology for obstructive jaundice in patients with unresectable biliary tract carcinomas. J Hepatobiliary Pancreat Surg. 2008;15:69-73. 